\title{
Myocardial contrast echocardiography in acute myocardial infarction: time to test for routine clinical use?
}

Coronary angiography has been used as the gold standard to determine whether reperfusion has been successful. TIMI (thrombolysis in myocardial infarction) grades have been developed for this purpose ${ }^{1}$ and have been shown to provide prognostic information. It has, however, been known for a quarter of a century that reflow in the infarct related artery does not necessarily imply tissue perfusion. ${ }^{2}$ It is also known, that regions within the myocardium that show poor tissue perfusion after reflow (no reflow or low reflow) have histological evidence of tissue necrosis. ${ }^{2}$ That myocardial contrast echocardiography (MCE) can define regions of no reflow was demonstrated nearly 15 years ago in a dog model. ${ }^{3}$

As is unfortunately often the case, the medical community either ignored or was unaware of these experimental data. Not surprisingly, therefore, the first report of MCE documenting no reflow in patients who underwent reperfusion for acute myocardial infarction (AMI) published about five years ago $^{4}$ was hailed as new knowledge. A number of clinical studies since then has confirmed these findings. ${ }^{5-7}$ Approximately a quarter to a third of patients with TIMI grade 3 flow on coronary angiography have poor tissue perfusion, which is associated with poor recovery in regional function and a worse prognosis. ${ }^{8}$ The paper by Czitrom et al in this issue ${ }^{9}$ adds to this body of knowledge.

MCE uses microbubbles that remain in the intravascular space. Because $90 \%$ of the myocardial microvasculature consists of capillaries, ${ }^{10}$ the spatial distribution of these bubbles in the myocardium provides an assessment of regional capillary integrity. Areas with necrosis are associated with capillary damage ${ }^{2}$ and impaired microvascular function. ${ }^{11}$ A non-invasive assessment of capillary structure and microvascular function, therefore, provides a simple means of assessing tissue perfusion and integrity. The ultimate test for the success of reperfusion is whether tissue perfusion has been achieved. MCE appears to be an ideal

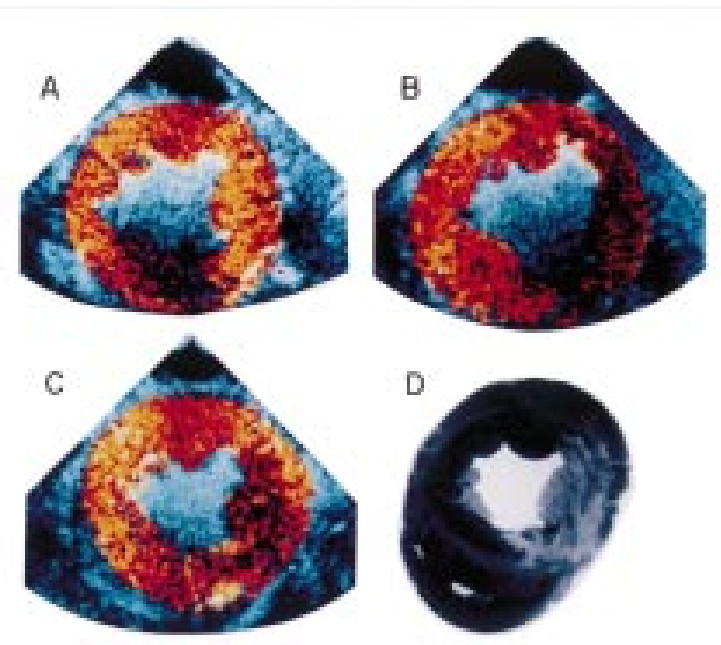

Figure 1 Examples of colour coded MCE images after a venous injection of a new second generation contrast agent in a dog. (A) Baseline. (B) During left circumflex artery occlusion. (C) After reperfusion (in the presence of a coronary vasodilator, to unmask abnormal microvascular function in the presence of reactive hyperaemia in the infarct zone).

(D) Infarct size on tissue staining. (Reproduced from Kaul S. Clinical applications of myocardial contrast echocardiography. In: Braunwald E, ed. Heart disease: a textbook of cardiovascular medicine. Update 1,

1977:1-10, with permission of W B Saunders Co.)

tool for assessing whether reperfusion has occurred, as well as determining the extent of necrosis.

The aforementioned clinical studies, ${ }^{5-8}$ and the one by Czitrom et al in this issue $e^{9}$ used intracoronary injections of microbubbles in the cardiac catheterisation laboratory. No commercially available microbubbles that can be administered intravenously have yet been approved for MCE. Several agents are currently being evaluated in phase II and

Table 1 Venous ultrasound contrast agents evaluated for MCE in the author's laboratory

\begin{tabular}{|c|c|c|c|c|c|c|}
\hline Name & Manufacturer & US distributor & $\begin{array}{l}\text { Size } \\
(\mu m)\end{array}$ & $\begin{array}{l}\text { Concentration } \\
\left(\times 10^{-9}\right)\end{array}$ & Shell composition & Gases \\
\hline Optison $\star$ & $\begin{array}{l}\text { Molecular Biosystems (San } \\
\text { Diego, California, USA) }\end{array}$ & $\begin{array}{l}\text { Mallinckrodt Medical } \\
\text { (St Louis, Missouri, USA) }\end{array}$ & 3.9 & 0.8 & Denatured albumin & Air and perfluoropropane \\
\hline Definity & $\begin{array}{l}\text { ImaRx Pharmaceutical } \\
\text { (Tuscon, Arizona, USA) }\end{array}$ & $\begin{array}{l}\text { Dupont Pharmaceuticals } \\
\text { (North Billerica, } \\
\text { Massachusetts, USA) }\end{array}$ & 2.5 & 1.2 & Lipids and surfactants & Air and perfluoropropane \\
\hline Imagent & $\begin{array}{l}\text { Alliance Pharmaceutical } \\
\text { (San Diego, California, } \\
\text { USA) }\end{array}$ & Schering & 5.0 & 0.5 & No shell (surfactant stabilised) & $\begin{array}{l}\text { Nitrogen and } \\
\text { perflurohexane }\end{array}$ \\
\hline Sonovue & Bracco sPA (Milan, Italy) & $\begin{array}{l}\text { Bracco Imaging (Princeton, } \\
\text { New Jersey, USA) }\end{array}$ & 2.5 & 0.2 & Lipids and surfactants & $\begin{array}{l}\text { Air and sulphur } \\
\text { hexafluoride }\end{array}$ \\
\hline Levovist† & Schering (Berlin, Germany) & $\begin{array}{l}\text { Berlex (Princeton, } \\
\text { New Jersey, USA) }\end{array}$ & $2-4$ & & $\begin{array}{l}\text { No shell (palmitic acid } \\
\text { stabilised) }\end{array}$ & Air \\
\hline N100100 & $\begin{array}{l}\text { Nycomed-Amersham (Oslo, } \\
\text { Norway) }\end{array}$ & Nycomed-Amersham & $3-5$ & & Protein and surfactant & Air and perfluorocarbon \\
\hline Quantison & Andaris (Nottingham, UK) & $\begin{array}{l}\text { Advanced Magnetics } \\
\text { (Princeton, New Jersey, } \\
\text { USA) }\end{array}$ & 3.2 & 1.5 & $\begin{array}{l}\text { Denatured albumin (thick } \\
\text { shell) }\end{array}$ & Air \\
\hline
\end{tabular}

Size and concentration are in vitro measurements.

*Approved in the USA and parts of Europe for left ventricular cavity opacification.

†Approved in Europe for Doppler signal enhancement. 

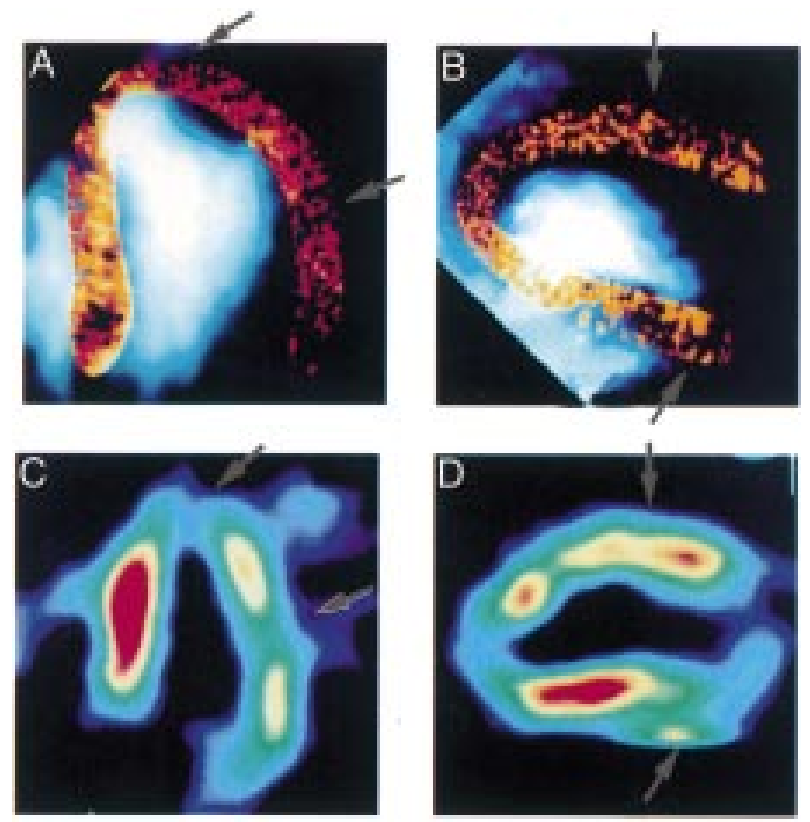

Figure 2 Examples of perfusion defects from two patients using apical four chamber (left panels) and apical two chamber (right panels) views. The top panels depict images obtained using MCE and the bottom panels show those obtained using SPECT. The MCE image from the apical two chamber view in this patient is placed on its side to correspond to the vertical two chamber view using SPECT. The first patient (left panels) had a large lateral defect that was identical on MCE and SPECT. The second patient (right panels) had vascular defects in the anteroapical and the upper posterior walls that were identical on MCE and SPECT.

(Reproduced from Kaul $S$, et al. Detection of coronary artery disease using myocardial contrast echocardiography: comparison with ${ }^{99 m}$ Tc-sestamibi single photon emission computed tomography. Circulation 1997;96:785-92, with permission of the American Heart Association.)

III studies (table 1) and some of them should become available by the year 2000 .

In animal models, these agents are able to define risk area during coronary occlusion, as well as determine the success of reperfusion and define the extent of necrosis after reflow. ${ }^{12}{ }^{13}$ Figure 1 illustrates MCE examples where $0.5 \mathrm{ml}$ of one of these agents (Optison) was administered intravenously in a dog at baseline, during coronary occlusion, and following reperfusion. In fig $1 \mathrm{~B}$, the risk area is clearly defined by MCE, while the success of reperfusion is documented in fig $1 \mathrm{C}$. Additionally, a low level of perfusion (low reflow or no reflow) within the centre of the reperfused myocardium is also documented in fig $1 \mathrm{C}$, which corresponds almost exactly with the infarct size (fig 1D). A clinical study with the same agent demonstrated the feasibility of defining perfusion defects in patients with previous infarctions. ${ }^{14}$

Figure 2 illustrates examples of perfusion defects on MCE from this study ${ }^{14}$ in a patient with a prior lateral infarction and in another patient with previous anteroapical and inferoposterior infarctions. The location and extent of the perfusion defects on MCE correspond closely with those seen on single photon emission computed tomography (SPECT).

Another setting where MCE can be used is in the diagnosis of AMI. Only one third of patients experiencing an AMI actually have diagnostic ECG changes on presentation to the emergency department. ${ }^{15}$ Therefore, at least in the USA, thrombolytic treatment is underused. For legal and safety reasons physicians are reluctant to give thrombolytics to patients without clear cut evidence of ongoing infarction. As shown in fig 1B, MCE could easily define a region of hypoperfusion and make a diagnosis of acute ischaemic syndrome.
In the USA, each year approximately five million people present to the emergency department with chest pain. ${ }^{16}$ Because the initial ECG is unreliable for excluding an $\mathrm{AMI}^{15}$ and because cardiac enzymes become positive much later, ${ }^{17}$ most of these patients are admitted to hospital for observation. Fewer than $20 \%$ of the admitted patients have an acute ischaemic syndrome and the rest are discharged the next day. This "rule out" AMI protocol costs US $\$ 10$ billion annually. MCE, where regional function ${ }^{18} 19$ and perfusion ${ }^{14}$ can be assessed online, could assist in selecting only high risk patients for hospital admissions and thus could dramatically reduce costs.

Given this information, how could one use MCE in patients with suspected AMI when intravenous microbubbles become available? Figure 3 lists various scenarios where MCE could be used. It could first document the occurrence of AMI by defining severe hypoperfusion. It could also help determine the size of the risk area. If the risk area is small because of occlusion of a small artery or abundant collateral flow, ${ }^{20}$ initial treatment can be conservative. If the risk area is large in size, thrombolysis or mechanical reperfusion should be instituted immediately.

Myocardial perfusion could then be reassessed immediately after thrombolysis. No change in the size of the risk area would indicate unsuccessful reperfusion and these patients could perhaps undergo rescue angioplasty. Complete or near complete myocardial opacification after attempted reperfusion would indicate either almost complete myocardial salvage or an underestimation of infarct size because of reactive hyperaemia. ${ }^{21} 22$ The most urgent question after attempted reperfusion is whether it has been successful and MCE can provide this information immediately.

Estimation of infarct size could be problematic immediately after reperfusion because of reactive hyperaemia. This phenomenon occurs only in the absence of a residual critical stenosis of the infarct related artery and abates within hours of reperfusion. Therefore, repeat MCE any time after 12 hours of reperfusion would provide an accurate assessment of infarct size. ${ }^{5}$ If the information concerning infarct size were required immediately, a coronary vasodilator could be administered. This procedure unmasks the abnormal microvascular function within the infarct zone and provides an accurate assessment of infarct size despite ongoing reactive hyperaemia (fig 1$).^{2122}$

The predominant opinion regarding the cause of the no reflow phenomenon is that it occurs secondary to tissue necrosis. ${ }^{2324}$ A contrary opinion is that it may be the cause of necrosis. ${ }^{25}$ In the former case, any attempt to alter microvascular function after reflow are unlikely to change infarct size. In the latter, pharmacological or other interventions aimed at improving microvascular function could salvage additional myocardium and reduce infarct size. Recent clinical studies using MCE have reported that the "low reflow" phenomenon seen after reperfusion and located at the periphery of the infarction can be reversed by verapamil $^{26}$ and nicorandil ${ }^{27}$ treatment, and that this reversal is associated with improved regional function and outcome. If these findings are confirmed in larger studies, then pharmacological treatment aimed towards reversal of microvascular dysfunction could be initiated in patients with low reflow to reduce infarct size. MCE could then be repeated to determine the success of this intervention.

A transmural zone of no reflow probably indicates a transmural AMI. Patients with this finding are likely to have infarct expansion, left ventricular dilatation, and heart failure. ${ }^{28}{ }^{29}$ They are, therefore, likely to benefit the most from early institution of angiotensin converting enzyme (ACE) inhibitor treatment. If the no reflow is not transmural, ACE inhibitors may not be necessary because normal 


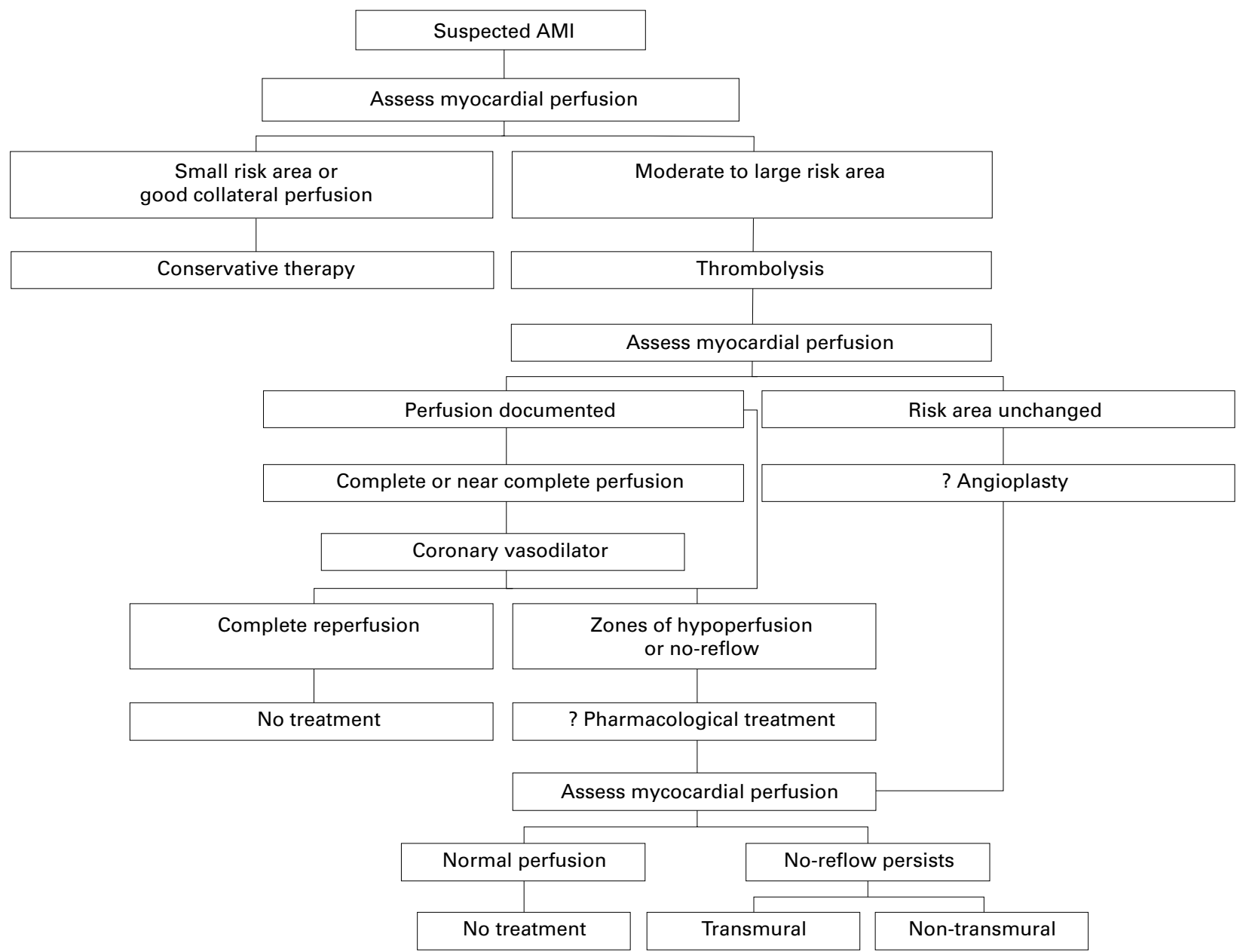

Figure 3 Possible scenarios where MCE could be used in patients with suspected or known AMI.

tissue is likely to buttress the infarct and prevent infarct expansion. A rationale such as this based on pathophysiological principles should prove to be superior to crude predictors such as left ventricular function and infarct location for selecting patients who would benefit the most from ACE inhibitors. ${ }^{30}$

The scenarios described here appear plausible given our knowledge of the pathophysiology of AMI and data from animal studies. Obviously, clinical studies are needed to confirm the value of MCE in each of these scenarios. Because each patient with AMI is unique, MCE has the potential for providing valuable information concerning the ischaemic and reperfused myocardium on a patient by patient basis. This information can then be used to individualise and optimise management. Intravenous contrast agents approved for MCE are eagerly awaited to test whether MCE should be used routinely in patients with AMI and other acute ischaemic syndromes.

Dr Kaul is supported in part by a grant (R01-HL48890) from the National Institutes of Health, Bethesda, Maryland, USA.

SANJIV KAUL

Cardiovascular Division,

Box 158, Medical Center

University of Virginia,

Charlottesville, VA 22908, USA

email:sk@virginia.edu

1 Cheseboro JH, Knatterud G, Roberts R, et al. Thrombolysis in myocardial infarction (TIMI) trial, phase I: comparison between intravenous plasminogen activator and intravenous streptokinase: clinical findings plasminogen activator and intravenous streptokinase:
through hospital discharge. Circulation 1987;76:142-54

2 Kloner RA, Ganote CE, Jennings RB. The "no-reflow" phenomenon after temporary coronary occlusion in the dog. F Clin Invest 1974;54:1496-508.
3 Kemper AJ, O'Boyle JE, Cohen CA, et al. Hydrogen peroxide contrast echocardiography: quantification in vivo of myocardial risk area during coronary occlusion and the necrotic area remaining after myocardial reperfusion. Circulation 1984;70:309-17.

4 Ito $\mathrm{H}$, Tomooka T, Sakai N, et al. Lack of myocardial perfusion immediately after successful thrombolysis: a predictor of poor recovery of left ventricular function in anterior myocardial infarction. Circulation 1992;85:1699-705.

5 Ragosta M, Camarano GP, Kaul S, et al. Microvascular integrity indicates myocellular viability in patients with recent myocardial infarction: new in-sights using myocardial contrast echocardiography. Circulation 1994;89: 2562-9

6 Lim Y-J, Nanto S, Masuyama T, et al. Myocardial salvage: its assessment and prediction by the analysis of serial myocardial contrast echocardiograms in patients with acute myocardial infarction. Am Heart f 1994;128:649-56.

7 Agati L, Voci P, Bilotta F, et al. Influence of residual perfusion within the infarct zone on the natural history of left ventricular dysfunction after acute myocardial infarction: a myocardial contrast echocardiographic study. $\mathcal{F} \mathrm{Am}$ Coll Cardiol 1994;24:336-42

8 Ito $\mathrm{H}$, Okamura A, Iwakura K, et al. Myocardial perfusion patterns related to thrombolysis in myocardial infarction grades after coronary angioplasty in patients with acute anterior wall myocardial infarction. Circulation 1996; 93:1993-9.

9 Czitrom D, Karila-Cohen D, Brochet E, et al. Acute assessment of microvascular perfusion patterns by myocardial contrast echocardiography during myocardial infarction: relation to timing and extent of functional recovery. Heart 1999;81:12-16.

10 Kassab GS, Lin DH, Fung YB. Morphometry of pig coronary venous system. Am f Physiol 1994;267:H2100-13.

11 Johnson WB, Malone SA, Pantely GA, et al. No reflow and extent of infarction during maximal vasodilation in the porcine heart. Circulation 1988;78: 462-72.

12 Firschke C, Lindner JR, Wei K, et al. Myocardial perfusion imaging in the setting of coronary artery stenosis and acute myocardial infarction using venous injection of FS-069, a second generation echocardiographic contrast agent. Circulation 1997;96:959-67.

13 Lindner JR, Firschke C, Wei K, et al. Myocardial perfusion characteristics and hemodynamic profile of MRX-115, a venous echocardiographic contrast agent, during acute myocardial infarction. $7 \mathrm{Am}$ Soc Echocardiogr 1998;11:36-46.

14 Kaul S, Senior R, Dittrich H, et al. Detection of coronary artery disease using myocardial contrast echocardiography: comparison with ${ }^{99 \mathrm{~m}} \mathrm{Tc}$-sestamibi single photon emission computed tomography. Circulation 1997;96:785-92.

15 Short $D$. The earliest electrocardiogrphic evidence of myocardial infarction. Br Heart f 1970;32:6-15.

16 Lee TH, Cook EF, Weisberg MG, et al. Acute chest pain in the emergency room: identification of low-risk patients. Arch Intern Med 1985;145:65-9. 
17 Rolet JWT, Terwelle HF, Van Capella FJL, et al. Infarct size estimation from serial CK MB determinations: peak activity and predictability. Br Heart $\mathcal{F}$ serial CK MB deter.

18 Sabia P, Afrookteh A, Touchstone DA, et al. Value of regional wall motion abnormality in the emergency room diagnosis of acute myocardial infarction: a prospective study using two-dimensional echocardiography. Circulation 1991;84(suppl I):85-92.

19 Sabia P, Abbott RD, Afrookteh A, et al. The importance of two-dimensional echocardiographic assessment of left ventricular systolic function in patients presenting to the emergency room with cardiac-related symptoms. Circulation 1991;84:1615-24.

20 Sabia PJ, Powers ER, Ragosta M, et al. An association between collateral blood flow and myocardial viability in patients with recent myocardial infarction. N Engl f Med 1992;372:1825-31.

21 Villanueva FS, Glasheen WP, Sklenar J, et al. Characterization of spatial patterns of flow within the reperfused myocardium using myocardial contrast echocardiography: implications in determining the extent of myocardial salvage. Circulation 1993;88:2596-606.

22 Villanueva FS, Camarano G, Ismail S, et al. Coronary reserve abnormalities during post-infarct reperfusion: implications for the timing of myocardial during post-infarct reperfusion: implications for the timing of myocardial
con-trast echocardiography to assess myocardial viability. Circulation 1996; con-trast echo

23 Fishbein MC, Maclean D, Moroko PR. The histopathologic evolution of myocardial infarction. Chest 1978;73:843-9.
24 Kloner RA, Rude RE, Carlson N, et al. Ultrastructural evidence of microvascular damage and myocardial cell injury after coronary artery occlusion: which comes first? Circulation 1980;62:945-52

25 Tillmanns H, Leinberger H, Neumann FJ, et al. Myocardial microcirculation in the beating heart-in vivo microscopic studies. In: Spaan JAE, Bruschke AVG, Gittenberger-de Groot AC, eds. Coronary circulation. Dortrecht: Martin Nijhoff Publishers, 1987:88-94.

26 Taniyama $\mathrm{Y}$, Ito $\mathrm{H}$, Iwakura $\mathrm{K}$, et al. Beneficial effect of intracoronary verapamil on microvascular and myocardial salvage in patients with acute myocardial infarction. 7 Am Coll Cardiol 1997;30:1193-9.

27 Taniyama $\mathrm{Y}$, Ito $\mathrm{H}$, Iwakura $\mathrm{K}$, et al. Intravenous nicorandil augments micro-vascular and myocardial salvage and reduces complications in patients with acute myocardial infarction [abstract]. Circulation 1997; 96(suppl I):I-748.

28 Eaton LW, Weiss JL, Bulkley BH, et al. Regional cardiac dilatation after acute myocardial infarction. N Engl f Med 1979;300:57-62.

29 Pirolo JS, Hutchins GM, Moore GW. Infarct expansion: pathologic analysis of 204 patients with single myocardial infarct. F Am Coll Cardiol 1986;7:349-54.

30 ACE Inhibitor Myocardial Infarction Collaborative Group. Indications for ACE inhibitors in the early treatment of acute myocardial infarction. Systemic overview of individual data from 100,000 patients in randomized trials. Circulation 1998;97:2202-12.

\section{Embryology of the heart}

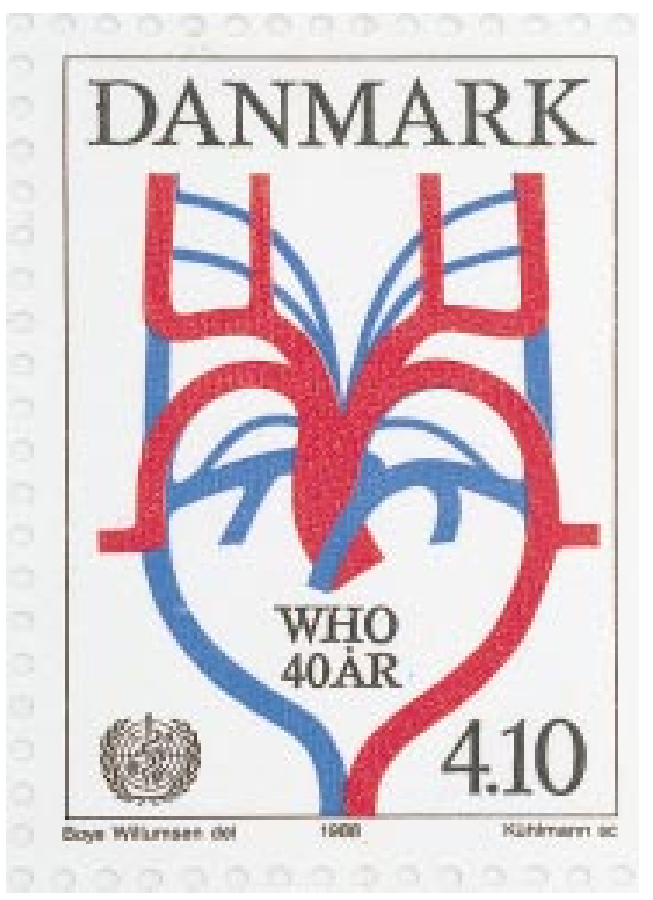

A unique design is seen in the Danish 1988 stamp issued to commemorate the 40th anniversary of the World Health Organisation. It was released on 7 April-World Health Day-and features the development of the arterial trunks and brachiocephalic arteries. The six paired arches are shown forming the definitive vasculature.

M K DAVIES A HOLLMAN 